\title{
Ensino de Computação de Forma Multidisciplinar em Disciplinas de História no Ensino Fundamental - Um Estudo de Caso
}

\author{
Title: Teaching Computing in a Multidisciplinary Way in History Classes in Elementary Schools - \\ A Case Study
}

Nathalia da Cruz Alves

Universidade Federal de Santa Catarina

Departamento de Informática e Estatística

nathaliaalves@grad.ufsc.br

Pedro Eurico Rodrigues

Universidade de São Paulo

Escola Autonomia

pedro.eurico.rodrigues@gmail.com

Adriano F. Borgatto

Universidade Federal de Santa Catarina

Departamento de Informática e Estatística

adriano.borgatto@ufsc.br
Christiane Gresse von Wangenheim

Universidade Federal de Santa Catarina

Departamento de Informática e Estatística

c.wangenheim@ufsc.br

Jean Carlo R. Hauck

Universidade Federal de Santa Catarina

Departamento de Informática e Estatística

jean.hauck@ufsc.br

Resumo Apesar da computação estar presente em praticamente todos os setores da sociedade, ainda existe uma carência de conhecimento e interesse no aprendizado dessa área, em grande parte devido à ausência do ensino da computação no Ensino Fundamental. Nesse sentido, o ensino focando somente na alfabetização digital não é mais suficiente, pois já no Ensino Fundamental precisa-se ensinar a proficiência digital, incluindo o pensamento computacional e a programação para preparar indivíduos a lidar com os desafios da era digital. Assim, existe atualmente uma tendência mundial de esforços concentrados no ensino de computação para esta faixa etária, sendo que a abordagem multidisciplinar, unindo a computação a outras disciplinas já inseridas no currículo escolar, tem se mostrado uma forma eficiente e eficaz de aprendizagem. Nesse contexto, a presente pesquisa propõe uma unidade instrucional para o ensino de computação no Ensino Fundamental de forma multidisciplinar, inserida na disciplina de História e estudos sociais, seguindo as diretrizes do currículo para o ensino de computação K-12 e usando Scratch como ferramenta. A unidade instrucional é desenvolvida seguindo uma abordagem de design instrucional e é aplicada e avaliada em um estudo de caso envolvendo quatro turmas no quinto e sétimo anos do Ensino Fundamental de uma escola em Florianópolis/SC. Os resultados observados indicam que a unidade instrucional e o uso do Scratch possibilitam a aprendizagem de conceitos básicos de computação (especificamente de programação) de forma eficaz e divertida e despertam o interesse e motivação dos alunos para esta área de conhecimento.

Palavras-Chave: Ciência da Computação, Ensino de História, Ensino Fundamental, Scratch, Programação, Pensamento Computacional.

\footnotetext{
Abstract Despite computing being virtually present in all sectors of our society, there is still a lack of knowledge and interest in learning about computing, in general due to the absence of the teaching of computing in elementary school. Teaching computing focusing only on digital literacy is no longer enough, as already in elementary school digital fluency need to be taught, including computational thinking and programming to prepare individuals adequately to deal with the challenges of the digital age. Thus, there is currently a global trend of concentrated efforts on computing education for this age group, and the multidisciplinary approach, combining computing to other disciplines already present within the scholar curriculum, has proven to be an efficient and effective way of teaching. In this context, the present study proposes an instructional unit for computing education in elementary school in a multidisciplinary way, integrated in
} 
history classes, following the K-12 curriculum guidelines for computer education and using the Scratch environment. The instructional unit is developed following an instructional design approach and is implemented and evaluated through a case study involving four classes in the fifth and seventh grades of an elementary school in Florianópolis/SC. The results indicate that the instructional unit and the use of Scratch enable the learning of basic computing concepts (specifically programming) in an effective and entertaining way and attract the interest and motivation of students to this knowledge area.

Keywords: Computer Science, History Teaching, Elementary School, Scratch, Programming, Computational thinking.

\section{Introdução}

A computação vem se tornando cada vez mais onipresente na vida do ser humano, sendo atualmente uma das áreas em que mais se criam empregos. Ter conhecimentos sobre os conceitos fundamentais da computação, permite às pessoas não se restringirem apenas ao uso de ferramentas da computação, mas adquirirem capacidade criativa. Assim, para terem uma formação que corresponda às demandas do século XXI, faz-se necessário o entendimento de, pelo menos, os princípios da ciência da computação [1]. Independentemente da área de atuação de um profissional, seja artes, medicina, comunicações, ciências exatas, entre outras; para que seja produtivo e competitivo, é imprescindível além de conhecer ferramentas digitais disponíveis, ser crítico e autônomo, saber se adaptar e adquirir novas habilidades para atingir seus objetivos [2].

Desse modo, é importante que as crianças possam começar a aprender computação já no Ensino Fundamental. No Ensino Fundamental, normalmente tem-se um enfoque apenas na utilização da TI - Tecnologia da Informação (IT literacy ou alfabetização digital), que se trata da capacitação dos alunos para o entendimento da tecnologia comum, isto é, saber usar aplicações do dia-adia como processadores de textos e e-mails [2]. No cenário moderno, isto já não é mais suficiente, é necessário ensinar também a proficiência digital (IT fluency), que se refere à capacidade de aprender, adaptar e aplicar novas tecnologias de forma produtiva [2]. Isto é necessário devido à velocidade com que novas aplicações surgem $\mathrm{e}$ a capacidade de processamento dos computadores e outros dispositivos aumenta, gerando desafios frequentes que requerem das pessoas capacidade de adaptação e evolução contínuas.

Ensinar a computação no Ensino Fundamental pode incluir várias áreas de conhecimento, conforme as diretrizes de currículo K-12 [1] (veja Fig. 1). Assim, espera-se que o aluno aprenda o pensamento computacional - que consiste numa abordagem para resolver problemas numa forma que pode ser implementada num computador envolvendo um conjunto de conceitos, como: abstração,

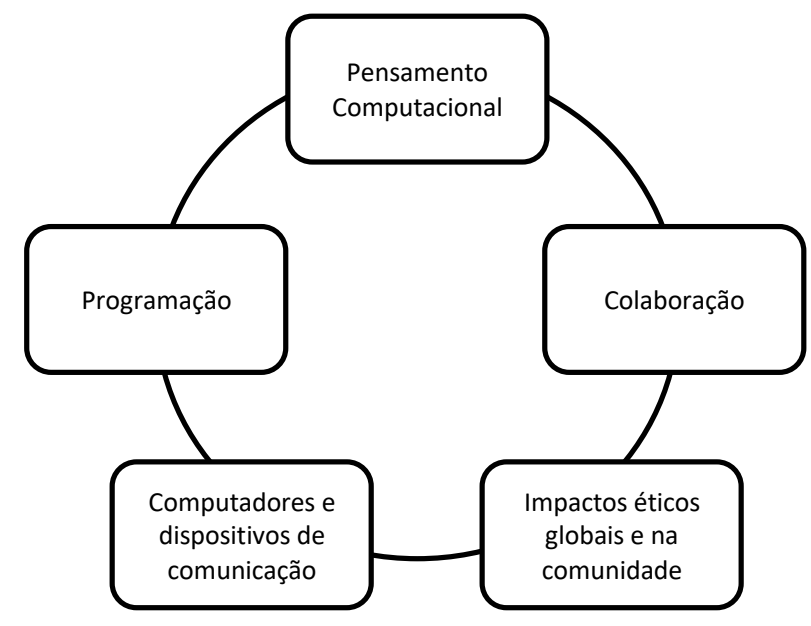

Figura 1: Áreas de conhecimento no ensino de computação [1].

recursão, iteração, etc. - além de aprender a prática de computação, incluindo a habilidade de explorar o uso de programação para resolver problemas e utilizar ferramentas de software adequadas para resolver problemas algorítmicos e computacionais [1]. Outras áreas importantes a serem aprendidas são a colaboração/trabalho em equipe, computadores e dispositivos de comunicação, e conhecimento referente aos impactos éticos, globais e na comunidade do uso das tecnologias.

Atualmente a inclusão do ensino de computação no Ensino Fundamental é uma tendência mundial, sendo que já existem diversas iniciativas nesse sentido, como, por exemplo, Code.org [3] e Scratch [4]. Porém, no Brasil, atualmente o ensino de computação ainda não é incluído na grade curricular [5], e a sua inclusão tem sido dificultada por diversos fatores. Um fator que dificulta a inserção de aulas de computação é a falta de tempo disponível nas grades curriculares já lotadas pelas disciplinas que devem ser ministradas pela LDB - Lei de Diretrizes e Bases da Educação - Lei 9.394/96. Existem ainda, certos "mitos" em relação à tecnologia, como por exemplo, muitas vezes é confundido o uso de tecnologia com a aplicação de técnicas que diminuem/substituem a atividade mental das pessoas [5]. Contudo, mesmo quando é um computador que executa estas operações, faz-se necessá- 
ria uma decisão por parte do utilizador, que é feita por meio da atividade mental. Isto não pode ser realizado pelas máquinas, já que estas ainda não possuem a capacidade de tomar todas as decisões complexas com autonomia [5]. Além disso, existe também a falta de professores de computação para o Ensino Fundamental [6], o que dificulta a implantação de propostas relacionadas à computação [5].

Neste contexto, atualmente no Ensino Fundamental, uma solução pode ser o ensino da computação de forma multidisciplinar [7], combinando ou envolvendo várias disciplinas acadêmicas para abordar um tema ou problema, também chamada de interdisciplinaridade fraca. Segundo Santomé, a multidisciplinaridade ou interdisciplinaridade fraca é o primeiro nível de integração entre duas ou mais disciplinas. Ela ocorre quando, para solucionar um problema "busca-se informação e ajuda em várias disciplinas, sem que tal interação contribua para modificá-las ou enriquecê-las" [7].

Com esta visão, no presente trabalho, é elaborada uma unidade instrucional visando o desenvolvimento de um jogo digital sobre conteúdo da disciplina de História. Em relação à disciplina de História o objetivo geral é que o aluno compreenda a realidade nas diversas dimensões temporais, destacando questões regionais, nacionais e mundiais das diferenças entre culturas e modos de viver/pensar/fazer. Em relação ao ensino da computação enfoca-se o ensino do pensamento computacional, prática computacional e da colaboração. Para operacionalizar o ensino de programação é utilizada a ferramenta Scratch [4], um ambiente para introduzir a programação de modo simples para crianças que não possuem nenhum tipo de experiência prévia neste assunto [8]. O Scratch possibilita a programação de histórias interativas, jogos e animações de maneira fácil e intuitiva. Atualmente o Scratch possui uma comunidade que abrange mais de 150 países e traduções em mais de 40 idiomas, incluindo a língua portuguesa, facilitando a aprendizagem para alunos que ainda não possuem uma compreensão básica da língua inglesa. $\mathrm{O}$ site do Scratch possui mais de 10 milhões de projetos compartilhados e mais de 7 milhões de usuários ativos, dos quais 155 mil são brasileiros [4].

Muitos estudos têm demonstrado que o Scratch contribui de forma positiva para o ensino de computação nas escolas $[9,10,11]$. Contudo, a maioria desses estudos foi conduzida sobre o uso do Scratch para ensinar exclusivamente conceitos de computação $[8,10,11]$ ou de forma multidisciplinar em disciplinas na área de ciências exatas, como matemática $[12,13]$. Basicamente não foram encontrados estudos relevantes relacionados a aplicação do Scratch para o ensino na área de ciências humanas, como na disciplina de História e estudos sociais. Foi encontrada somente uma proposta de ensino computação na área de história e geografia [14]. Porém, a proposta não apresenta nenhum tipo de avaliação do impacto da sua aplicação.
Foram encontradas também outras propostas com o mesmo intuito de ensino de computação no Ensino Fundamental, porém, fazendo uso de outras ferramentas, como, por exemplo, o App Inventor [25]. Nessa proposta foram abordados aspectos do pensamento computacional alinhados ao pensamento histórico para introduzir os alunos à ciência da computação dentro da disciplina de História desenvolvendo um aplicativo de narrativa histórica [25]. Outras propostas de inserção de TI nas disciplinas de História, como p.ex. mundos virtuais 3D [26] ou videogames [27] estão fora do foco deste trabalho como se referindo somente ao uso de tecnologia, mas não a criação de software pelos alunos. Em geral, também observamos a falta de uma definição clara tanto dos objetivos de aprendizagem e do design de unidades instrucionais quanto a falta de disponibilidade de um conjunto de materiais didáticos para acompanhar estas propostas $[25$, 28].

Assim, para atingir uma aprendizagem não só eficaz, na qual os objetivos de aprendizagem são totalmente atingidos; mas também eficiente, otimizando a quantidade de esforço, tempo e recursos necessários para atingir os objetivos de aprendizagem; é necessário que uma unidade instrucional multidisciplinar envolvendo computação e História seja preparada de forma a ser ao mesmo tempo motivadora e divertida e, ser avaliada de acordo em um processo de design instrucional [15].

Neste contexto, o presente artigo apresenta um estudo de caso do desenvolvimento e aplicação de uma unidade instrucional para o ensino de computação para crianças do Ensino Fundamental de forma multidisciplinar em disciplinas de História (para alunos do $7^{\circ}$ ano) e estudos sociais (para alunos do $5^{\circ}$ ano em que são ensinados conteúdos tanto de história como de geografia) utilizando Scratch. A principal pergunta de pesquisa consiste em descobrir se é viável desenvolver uma unidade instrucional para ensinar computação integrada à disciplina de História e estudos sociais do Ensino Fundamental, com o uso do Scratch. A unidade instrucional tem como característica principal a multidisciplinaridade [7], pois possui um grau de integração entre o conteúdo da disciplina de História e da computação em que há transferência de métodos, conceitos e informações. A unidade foi aplicada e avaliada sistematicamente em uma escola na cidade de Florianópolis/SC. Durante a aplicação da unidade instrucional as crianças desenvolveram um jogo digital, de forma integrada ao conteúdo da disciplina de História.

O presente estudo de caso faz parte da iniciativa Computação na Escola (www.computacaonaescola.ufsc.br) coordenada pelo Instituto Nacional de Convergência Digital (INCoD) do Departamento de Informática e Estatística (INE) da Universidade Federal de Santa Catarina (UFSC) em parceria com o Instituto Federal de Santa Catarina (IFSC). 


\section{Metodologia de pesquisa}

O objetivo desta pesquisa é o desenvolvimento, a aplicação e a avaliação de uma unidade instrucional para o ensino de computação de forma multidisciplinar no Ensino Fundamental. Para atingir este objetivo é realizado um estudo de caso exploratório para compreender os fenômenos observados durante as aplicações da unidade instrucional em um contexto particular e identificar direcionamentos para trabalhos futuros (Fig. 2).

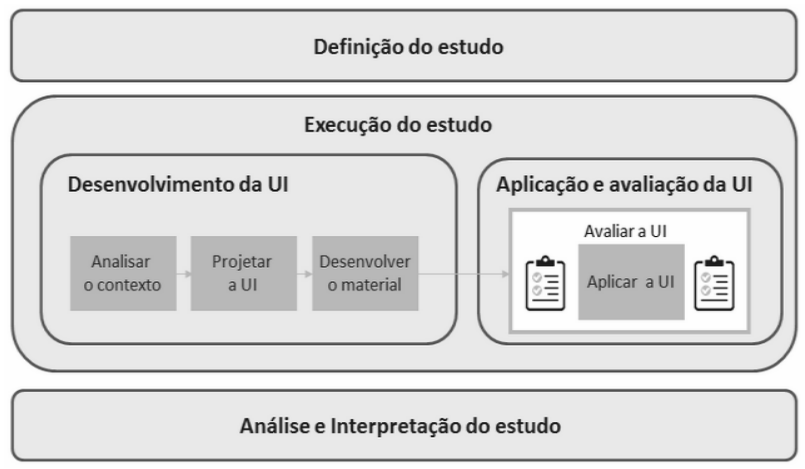

Figura 2: Metodologia de pesquisa

O estudo de caso é realizado conforme os procedimentos propostos por Yin [16] e Wohlin et al. [17]:

Definição do estudo: $O$ estudo é definido em termos do objetivo e perguntas de pesquisa e o design de pesquisa. A partir do objetivo e das perguntas de análise são sistematicamente derivadas as medidas para a coleta de dados utilizando o método GQM [18]. Para a operacionalização da coleta de dados são definidos instrumentos de coleta de dados para todas as medidas definidas.

Execução do estudo: A execução do estudo é realizada adotando o modelo ADDIE [15] como abordagem para o design instrucional. Em uma primeira etapa a unidade instrucional é desenvolvida. Para isto, são primeiramente caracterizados os aprendizes e o ambiente em que a unidade instrucional acontecerá. São então levantadas as necessidades de aprendizagem e com base nessas informações são definidos os objetivos de aprendizagem. De acordo com a análise de contexto, é projetada a unidade instrucional, definindo o seu conteúdo, a sequência e os métodos instrucionais a serem adotados. Em seguida, o material instrucional é desenvolvido. Durante a segunda etapa da execução do estudo, a unidade instrucional é aplicada na prática e avaliada, coletando-se os dados conforme a definição do estudo.

Análise e Interpretação do estudo: Nesta etapa são analisados os dados em relação às perguntas de pesquisa, usando métodos quantitativos e qualitativos. Ao final, os resultados são interpretados e discutidos.

\section{Desenvolvimento da unidade instru- cional}

A unidade instrucional para o ensino multidisciplinar de computação é desenvolvida seguindo uma abordagem de design instrucional [15], incluindo as principais etapas de: Análise da unidade instrucional, Design da unidade instrucional e o Desenvolvimento do material instrucional. As etapas de elaboração são descritas a seguir.

\subsection{Análise da unidade instrucional}

Seguindo o design instrucional são inicialmente estudados os perfis dos aprendizes e o ambiente e assim, a partir desses, definidos os objetivos de aprendizagem.

Aprendizes: $O$ público alvo deste trabalho são alunos do Ensino Fundamental de uma escola do município de Florianópolis/SC, com idade entre 8 e 14 anos. Tipicamente, a maioria dos alunos nessa idade já possui conhecimento e habilidades no uso de computadores e outros dispositivos devido ao acesso à internet, redes sociais, jogos digitais, vídeos, músicas em casa. Os alunos tipicamente também já sabem usar computadores e dispositivos periféricos por meio do uso de dispositivos eletrônicos (celulares, computadores, tablets) em casa e também por meio de aulas de informática tradicionais nas escolas com foco na utilização de TI (IT literacy). No que se refere às competências relacionadas à computação, especificamente o que se refere à programação, alguns alunos já conhecem como se cria um programa de computador, mas poucos sabem fazê-lo. Em termos de conhecimento geral, os alunos do Ensino Fundamental dessa escola já são alfabetizados e também possuem domínio inicial do inglês. Em relação à História, os alunos já dominam algumas noções temporais, têm conhecimento sobre a história local e os mais velhos (após 10 anos de idade) já conhecem a história das civilizações antigas [19].

Ambiente: Atualmente, muitas escolas têm computadores ou notebooks, tipicamente utilizando como sistema operacional Linux Educacional numa maior escala que uma versão do Windows [20]. As escolas também tipicamente fornecem acesso à internet por meio de uma rede sem fio. Mesmo tendo comumente um técnico de TI na escola dando suporte ao uso dos computadores, a maioria das escolas não possui professores de computação [6]. Os computadores são tipicamente utilizados por professores de outras áreas para trabalhos digitais ensinando também o uso de TI (TI literacy), como, por exemplo, editando textos, fazendo apresentações, blogs, etc. Na escola deste estudo de caso, as disciplinas de História ( $7^{\circ}$ ano) e estudos sociais $\left(5^{\circ}\right.$ ano) são tipicamente realizadas com 2 horas/aula semanais no Ensino Fundamental, sendo ministrados por um professor de História. As turmas possuem em média 25 - 30 alunos. 
Objetivos de aprendizagem: O objetivo desta unidade instrucional é ensinar conceitos básicos da computação por meio da criação de um jogo com Scratch voltado ao conteúdo da disciplina de História, adaptado de acordo com as diretrizes do currículo de referência da ACM CSTA K-12. Aqui o foco principal é no ensino a conceitos da programação (laços, condicionais, tratamento de eventos, passagem de mensagens, concorrência, entre outros), aplicar o ciclo de engenharia de software, conhecer conceitualmente linguagens de programação e realizar práticas de colaboração. $\mathrm{O}$ aluno também deve conhecer o que é e como funciona um algoritmo e princípios na solução de problemas. Em relação ao ambiente Scratch, o aluno deverá saber descrever o que é, o que pode ser feito com o ambiente, fazer uso do ambiente (entrar no site, criar programa, acessar programas, compartilhar programas), criar um jogo dentro do ambiente e utilizá-lo para compartilhar e comentar jogos desenvolvidos. Em termos de conteúdo, visou-se a integração do ensino de computação ao programa geral de ensino do Ensino Fundamental da disciplina de História. Dentro do conteúdo de História o aluno deve compreender a realidade nas múltiplas dimensões temporais para o desenvolvimento de um jogo. São destacadas as questões regionais em tópicos sobre alimentação/cultura indígena em Santa Catarina e, mundiais em tópicos sobre Civilizações Antigas. O aluno deve compreender as diferenças entre culturas e modos de viver/pensar/fazer. A Tabela 1 apresenta esses objetivos.

Objetivos gerais de aprendizagem: Entender conceitos básicos da computação, principalmente relacionados à prática/programação e ao pensamento computacional, usar o ambiente de desenvolvimento Scratch para criar jogos reforçando os conhecimentos sobre a realidade histórica em diferentes épocas.

\begin{tabular}{l|l}
\hline $\begin{array}{c}\text { Ao final da unidade } \\
\text { instrucional o aluno } \\
\text { será capaz de: }\end{array}$ & \multicolumn{1}{c}{$\begin{array}{c}\text { Relação aos currículos de } \\
\text { referência [1, 5] }\end{array}$} \\
\hline $\begin{array}{l}\text { [OC1] Usar os passos } \\
\text { básicos da solução de } \\
\text { problemas algorítmi- } \\
\text { cos/engenharia de } \\
\text { software para projetar } \\
\text { resoluções de proble- } \\
\text { mas. }\end{array}$ & $\begin{array}{l}\text { - Usar os passos básicos para a solução de } \\
\text { problemas algorítmicos para projetar } \\
\text { resoluções de problemas (Por exemplo } \\
\text { declaração e exploração do problema, } \\
\text { examinação de casos da amostra, projeto, } \\
\text { implementação de uma solução, testes e } \\
\text { avaliação). (Pensamento computacional) } \\
\text { - Fazer uso da abstração para decompor } \\
\text { um problema em subproblemas. (Pensa- } \\
\text { mento computacional) }\end{array}$ \\
\hline $\begin{array}{l}\text { [OC2] Descrever e } \\
\text { analisar uma sequência } \\
\text { de instruções a ser } \\
\text { seguida. }\end{array}$ & $\begin{array}{l}\text { - Descrever e analisar uma sequência de } \\
\text { instruções a ser seguida (Por exemplo } \\
\text { descrever o comportamento a ser seguido } \\
\text { por um personagem de um jogo através } \\
\text { de regras e algoritmos). (Pensamento } \\
\text { computacional) }\end{array}$ \\
\hline $\begin{array}{l}\text { [OC3] Entender e } \\
\text { aplicar conceitos de }\end{array}$ & $\begin{array}{l}\text { - Implementar soluções de problema } \\
\text { utilizando uma linguagem de programa- }\end{array}$ \\
\hline
\end{tabular}

\begin{tabular}{|c|c|}
\hline programação. & $\begin{array}{l}\text { ção, incluindo: laços, comandos condici- } \\
\text { onais, expressões lógicas, variáveis e } \\
\text { funções. (Prática de computa- } \\
\text { ção/Programação) }\end{array}$ \\
\hline $\begin{array}{l}\text { [OC4] Usar o ambiente } \\
\text { Scratch para criar, } \\
\text { desenvolver e comparti- } \\
\text { lhar um jogo de Histó- } \\
\text { ria. }\end{array}$ & $\begin{array}{l}\text { - Projetar, desenvolver, publicar e apre- } \\
\text { sentar produtos utilizando recursos tecno- } \\
\text { lógicos que demonstram e comunicam } \\
\text { conceitos do currículo. (Prática de com- } \\
\text { putação/Programação) }\end{array}$ \\
\hline $\begin{array}{l}\text { [OC5] Colaborativa- } \\
\text { mente criar, desenvol- } \\
\text { ver, publicar e apresen- } \\
\text { tar produtos usando } \\
\text { recursos tecnológicos } \\
\text { que demonstram e } \\
\text { comunicam conceitos } \\
\text { do currículo. }\end{array}$ & $\begin{array}{l}\text { - Colaborativamente criar, desenvolver, } \\
\text { publicar e apresentar produtos, utilizando } \\
\text { recursos tecnológicos que demonstram e } \\
\text { comunicam conceitos do currículo. } \\
\text { (Colaboração) } \\
\text { - Colaborar com colegas, professores e } \\
\text { outros usando práticas de colaboração } \\
\text { como programação em pares, trabalho em } \\
\text { equipe e participando de atividades de } \\
\text { aprendizagem em grupo. } \\
\text { (Colaboração). }\end{array}$ \\
\hline $\begin{array}{l}\text { [OH1] Demonstrar } \\
\text { conhecimento sobre o } \\
\text { modo de vida de dife- } \\
\text { rentes grupos, em } \\
\text { diversos tempos e } \\
\text { espaços, em suas } \\
\text { manifestações culturais } \\
\text { e sociais, reconhecendo } \\
\text { semelhanças e diferen- } \\
\text { ças entre eles e seus } \\
\text { conflitos. }\end{array}$ & $\begin{array}{l}\text { - Situar acontecimentos históricos e } \\
\text { localizá-los em uma multiplicidade de } \\
\text { tempos. } \\
\text { - Conhecer e respeitar o modo de vida de } \\
\text { diferentes grupos, em diversos tempos e } \\
\text { espaços, em suas manifestações culturais, } \\
\text { econômicas, políticas e sociais, reconhe- } \\
\text { cendo semelhanças e diferenças entre } \\
\text { eles, continuidades e descontinuidades, } \\
\text { conflitos e contradições sociais; }\end{array}$ \\
\hline $\begin{array}{l}\text { [OH2] Utilizar fontes } \\
\text { históricas em suas } \\
\text { pesquisas escolares. }\end{array}$ & $\begin{array}{l}\text { - Dominar procedimentos de pesquisa } \\
\text { escolar e de produção de texto, aprenden- } \\
\text { do a observar e colher informações de } \\
\text { diferentes paisagens e registros escritos, } \\
\text { iconográficos, sonoros e materiais; }\end{array}$ \\
\hline
\end{tabular}

Tabela 1: Objetivos de aprendizagem de computação (OC) e História $(\mathrm{OH})$ da unidade instrucional.

\subsection{Design da unidade instrucional}

De acordo com a análise de contexto é projetada uma unidade instrucional (UI). Essa unidade é desenvolvida com o propósito de fazer com que o ensino da computação seja eficaz e ao mesmo tempo envolvente e motivador, expondo aos alunos a importância da computação e despertando o interesse para esta área. A unidade instrucional é desenvolvida de forma multidisciplinar, explorando a integração entre alguns dos conceitos práticos da computação (programação) e de conteúdos da disciplina de História.

De acordo com a disponibilidade de aplicação é definida uma unidade instrucional de 12 horas/aula. Na unidade instrucional são primeiramente apresentados conceitos básicos de programação e do ambiente Scratch, como: adicionar atores, usar comandos de movimento, usar condicionais e laços, fazer a criação e modificação do valor de uma variável, modificar a aparência de atores, tratamento de eventos, entre outros. Esses conceitos são 
ensinados passo a passo pelo instrutor por meio do ensino de um jogo do gênero ação, permitindo que os alunos já experimentem na prática a execução desses comandos durante a criação do jogo. Como ferramenta de programação é escolhida Scratch por ser uma ferramenta bastante intuitiva e fácil de usar, com grande popularidade [4].

Após a familiarização inicial, os alunos iniciam a criação de um jogo voltado ao conteúdo da disciplina de História. Nas turmas em que seria aplicado o estudo de caso, anteriormente às aulas de computação, o tema central foi abordado por meio da leitura e discussão nas aulas de História.

No $5^{\circ}$ ano, os alunos já estudaram história de Santa Catarina dentro da disciplina de estudos sociais e, no $7^{\circ}$ ano, os alunos já estudaram as sociedades antigas da Europa, Grécia e Roma Antiga dentro da disciplina de História. Os alunos podem livremente escolher o gênero e mecânica do jogo. Com o objetivo de dar ideias, são apresentados vários exemplos de jogos no Scratch relacionados ao tema da disciplina de História. Em seguida os alunos elaboram uma ideia de um jogo de algum tipo escolhido relacionado ao conteúdo da disciplina.

Assim, começam a conceber, programar e testar passo a passo o jogo em grupos de até 3 alunos. Ao final do desenvolvimento, os jogos são compartilhados no próprio ambiente Scratch. Todos os alunos podem jogar e fazer comentários sobre os jogos da turma. É feito um debate refletindo sobre a experiência dos alunos e do professor. O sequenciamento da UI, num resumo do plano de ensino, é apresentado na Tabela 2.

\begin{tabular}{|c|c|c|c|}
\hline \multicolumn{4}{|l|}{ Conteúdo } \\
\hline \multicolumn{4}{|c|}{$\begin{array}{l}\text { Aprender a utilizar o ambiente Scratch (entrar no site, criar progra- } \\
\text { ma, acessar programas, compartilhar programas). Conceber, progra- } \\
\text { mar e testar um jogo com Scratch ilustrando questões sobre civiliza- } \\
\text { ções europeias antigas ou cultura e história de Santa Catarina. Com- } \\
\text { partilhar e experimentar os jogos desenvolvidos pela turma. }\end{array}$} \\
\hline $\begin{array}{l}\text { Encontro } \\
(2 \text { horas })\end{array}$ & $\begin{array}{c}\text { Método } \\
\text { instrucional }\end{array}$ & Recursos & $\begin{array}{l}\text { Avalia- } \\
\text { ção }\end{array}$ \\
\hline Medição 1 & & $\begin{array}{l}\text { - Questionário } \\
\text { aluno pré-unidade }\end{array}$ & \\
\hline $\begin{array}{l}\text { 1.Introdução ao } \\
\text { Scratch }\end{array}$ & $\begin{array}{l}\text { - Atividade } \\
\text { prática passo }\end{array}$ & $\begin{array}{l}\text { - Guia do instru- } \\
\text { tor. }\end{array}$ & \\
\hline $\begin{array}{l}\text { - Programar um } \\
\text { jogo exemplo } \\
\text { com comandos } \\
\text { básicos. }\end{array}$ & $\begin{array}{l}\text { a passo } \\
\text { guiada pelo } \\
\text { instrutor. }\end{array}$ & $\begin{array}{l}\text { - Ambiente de } \\
\text { programação } \\
\text { Scratch. }\end{array}$ & \\
\hline $\begin{array}{l}\text { 2. Projeto de um } \\
\text { jogo sobre um } \\
\text { tema de história }\end{array}$ & $\begin{array}{l}\text { - Apresenta- } \\
\text { ção de jogos } \\
\text { exemplos }\end{array}$ & $\begin{array}{l}\text { - Exemplos de } \\
\text { jogos no Scratch. } \\
\text { - Ambiente de }\end{array}$ & \\
\hline $\begin{array}{l}\text { - Divisão de } \\
\text { grupos. }\end{array}$ & $\begin{array}{l}\text { pelo profes- } \\
\text { sor. }\end{array}$ & $\begin{array}{l}\text { programação } \\
\text { Scratch. }\end{array}$ & \\
\hline $\begin{array}{l}\text { - Concepção de } \\
\text { jogo (Escolha } \\
\text { do tipo e mecâ- } \\
\text { nicas do jogo e }\end{array}$ & $\begin{array}{l}\text { - Cada gru- } \\
\text { po/dupla } \\
\text { discute ideias } \\
\text { sobre o }\end{array}$ & $\begin{array}{l}\text { - Material instru- } \\
\text { cional das aulas de } \\
\text { História. }\end{array}$ & \\
\hline
\end{tabular}

\begin{tabular}{|c|c|c|c|}
\hline $\begin{array}{l}\text { do tema de } \\
\text { história). }\end{array}$ & $\begin{array}{l}\text { projeto do } \\
\text { jogo }\end{array}$ & & \\
\hline $\begin{array}{l}3,4 \text { e } 5 \text {. Pro- } \\
\text { gramação e } \\
\text { testes do jogo }\end{array}$ & $\begin{array}{l}\text { - Prática de } \\
\text { programação } \\
\text { e teste do } \\
\text { jogo pelos } \\
\text { gru- } \\
\text { pos/duplas. } \\
\text { - Professor } \\
\text { disponível } \\
\text { para tirar } \\
\text { dúvidas. }\end{array}$ & $\begin{array}{l}\text { - Exemplos de } \\
\text { jogos Scratch. } \\
\text { - Ambiente de } \\
\text { programação } \\
\text { Scratch. } \\
\text { - Material instru- } \\
\text { cional das aulas de } \\
\text { História. }\end{array}$ & $\begin{array}{l}\text { - Rubrica } \\
\text { para } \\
\text { avaliar os } \\
\text { projetos } \\
\text { dos } \\
\text { alunos. } \\
\text { - Ferra- } \\
\text { menta de } \\
\text { avaliação } \\
\text { Dr. } \\
\text { Scratch. }\end{array}$ \\
\hline $\begin{array}{l}\text { 6. Finalização } \\
\text { dos projetos } \\
\text { - Compartilha- } \\
\text { mento, experi- } \\
\text { mentação dos } \\
\text { jogos da turma. } \\
\text { - Debate sobre a } \\
\text { unidade }\end{array}$ & $\begin{array}{l}\text { - Jogos da } \\
\text { turma são } \\
\text { jogados pelos } \\
\text { alunos. } \\
\text { - Discussão. }\end{array}$ & & \\
\hline Medição 2 & & $\begin{array}{l}\text { - Questionário } \\
\text { aluno pós-unidade } \\
\text { - Questionário } \\
\text { instrutor pós- } \\
\text { unidade }\end{array}$ & \\
\hline
\end{tabular}

Tabela 2: Resumo do sequenciamento da unidade instrucional.

\subsection{Desenvolvimento do material instrucional}

De acordo com o plano de ensino definido foram desenvolvidos vários materiais instrucionais.

Guia do instrutor: Foi desenvolvido um guia para o instrutor indicando passo a passo como explicar o desenvolvimento de um jogo com Scratch com comandos básicos, também incluindo a instalação do Scratch off-line e a criação de contas e projetos no site do Scratch. (Vide Figura 3).

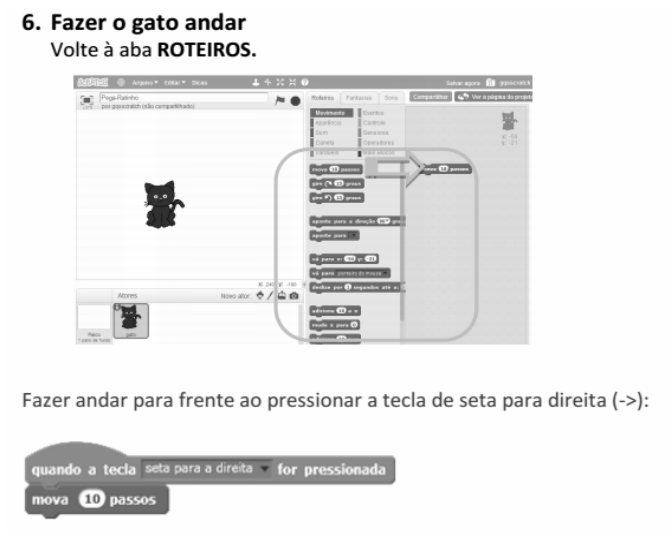

Testar: clique na bandeira verde e aperte a tecla da seta ->. Funcionou?

Figura 3: Guia do instrutor - Como programar o movimento de atores. 
Jogos exemplos: Foram desenvolvidos jogos exemplos de diversos gêneros relacionados a temas de história (vide Figura 4).

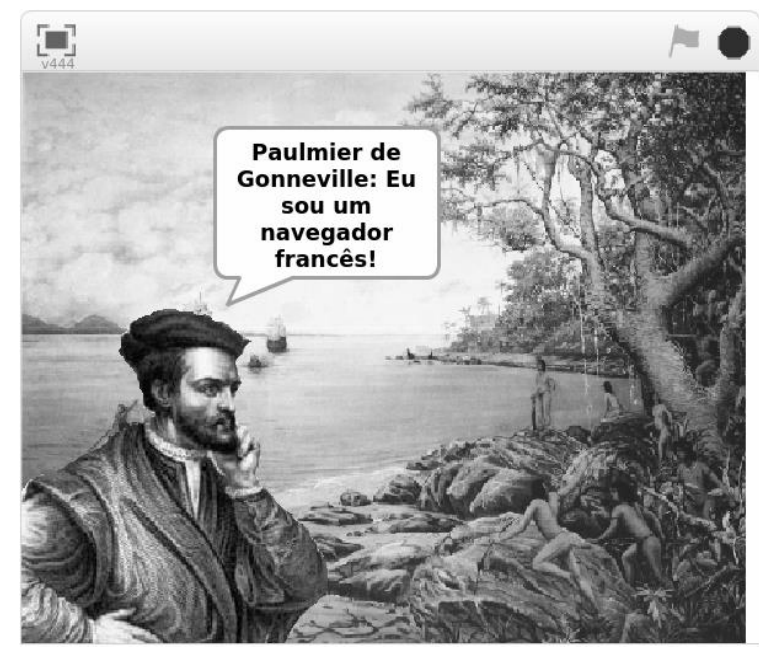

Figura 4: Jogo exemplo sobre história de Santa Catarina.

Rubrica: Documento que define os critérios de avaliação para medir o aprendizado dos alunos através dos jogos desenvolvidos (vide Figura 5). Rubricas podem ser usadas para prover feedback formativo dos alunos, para dar notas ou avaliar programas [29]. Elas são o meio de veicular expectativas e de dar notas de forma clara, honesta e rica em informação para o aluno, nas quais são descritos níveis de desempenho, de competências, na realização de tarefas.
Questionários de avaliação: Conforme o plano de medição voltado à avaliação da unidade instrucional em termos de percepção, autoavaliação e motivação do aluno antes/depois da unidade instrucional, foram elaborados para o aluno um questionário pré e um pós unidade (vide Figura 6). E, para avaliar a percepção do professor após a unidade instrucional, foi elaborado um questionário pós unidade.

Além desses materiais desenvolvidos especificamente para esta unidade, outros materiais foram utilizados incluindo o ambiente de programação Scratch [4] e o software de avaliação Dr. Scratch [21].

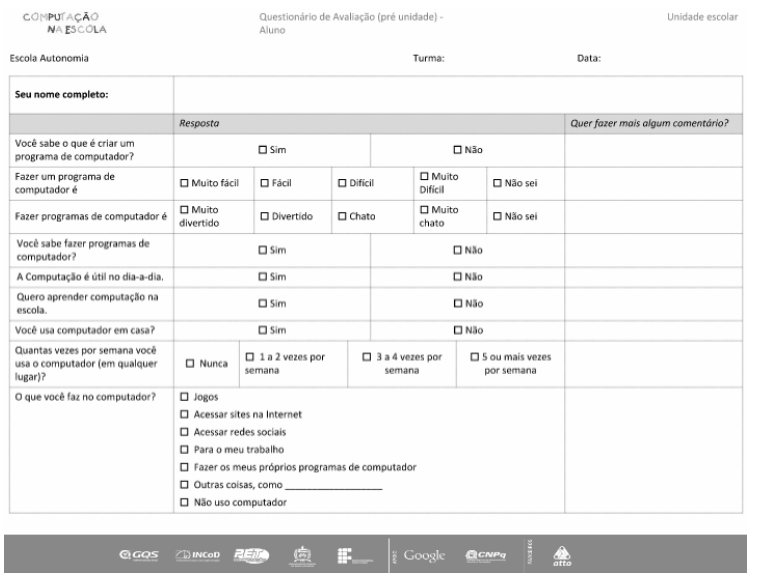

Figura 6: Primeira folha do questionário pré-unidade do aluno.
COMPUTAÇÃO NAESCOLA

\begin{tabular}{|c|c|c|c|c|c|}
\hline \multirow[t]{2}{*}{ Objetivo de aprendizagem } & \multirow[t]{2}{*}{ Item da rubrica } & \multirow[b]{2}{*}{ Excelente } & \multirow[b]{2}{*}{ Muito bom } & \multirow[b]{2}{*}{ Regular } & \multirow[b]{2}{*}{ Insuficiente } \\
\hline & & & & & \\
\hline $\begin{array}{l}\text { [01] Entender e usar os } \\
\text { passos básicos para a } \\
\text { solução de problemas } \\
\text { algorítmicos (declaração e } \\
\text { exploração do problema, } \\
\text { identificação de } \\
\text { exemplos, projeto, } \\
\text { implementação e testes). }\end{array}$ & $\begin{array}{l}\text { Execução do processo básico } \\
\text { de engenharia de } \\
\text { software(concepção) }\end{array}$ & $\begin{array}{l}\text { Aluno fez uso } \\
\text { significativo do processo } \\
\text { de concepção e usou o } \\
\text { tempo de projeto de } \\
\text { forma construtiva, } \\
\text { terminou cedo ou } \\
\text { adicionou elementos } \\
\text { adicionais. }\end{array}$ & $\begin{array}{l}\text { Aluno usou o processo } \\
\text { de concepção } \\
\text { (especificou o } \\
\text { problema, teve idéias, } \\
\text { escolheu uma solução, } \\
\text { construiu e testou, } \\
\text { apresentou resultados). } \\
\text { Tempo de projeto } \\
\text { usado de forma } \\
\text { construtiva, terminou as } \\
\text { tarefas dentro dos } \\
\text { prazos. }\end{array}$ & $\begin{array}{l}\text { Aluno tentou usar o } \\
\text { processo de concepção. } \\
\text { Tempo de projeto bem } \\
\text { usado às vezes e } \\
\text { cumpriu alguns prazos. }\end{array}$ & $\begin{array}{l}\text { Aluno não usou o } \\
\text { processo de concepção. } \\
\text { Não utilizou o tempo de } \\
\text { projeto bem e não } \\
\text { cumpriu prazos. }\end{array}$ \\
\hline $\begin{array}{l}\text { [09] Identificar modos em } \\
\text { que o trabalho em equipe e } \\
\text { a colaboração podem } \\
\text { apoiar a resolução de } \\
\text { problemas e a inovação. }\end{array}$ & $\begin{array}{l}\text { Colaboração e trabalho em } \\
\text { equipe }\end{array}$ & $\begin{array}{l}\text { Trabalhou muito bem } \\
\text { em equipe/ } \\
\text { programação em pares } \\
\text { e encontrou maneiras } \\
\text { de colaborar além de } \\
\text { estrutura da classe. }\end{array}$ & $\begin{array}{l}\text { Trabalhou muito bem } \\
\text { em equipes/ } \\
\text { programação em pares. }\end{array}$ & Colaborou às vezes. & Não colaborou. \\
\hline $\begin{array}{l}\text { [014] Construir um } \\
\text { programa como um } \\
\text { conjunto de instruções } \\
\text { passo a passo para serem }\end{array}$ & Avaliação geral & $\begin{array}{l}\text { Programa funciona } \\
\text { corretamente e não } \\
\text { demonstra nenhum } \\
\text { erro. }\end{array}$ & $\begin{array}{l}\text { Programa funciona } \\
\text { muito bem } \\
\text { demonstrando muito } \\
\text { poucos erros. }\end{array}$ & $\begin{array}{l}\text { Programa pode ter } \\
\text { vários erros e não } \\
\text { funciona perfeitamente. }\end{array}$ & $\begin{array}{l}\text { O programa não } \\
\text { funciona. }\end{array}$ \\
\hline
\end{tabular}

Figura 5: Primeira folha da rubrica para avaliação dos jogos. 


\section{Aplicação da unidade instrucional}

A unidade instrucional desenvolvida foi aplicada com duas turmas do $5^{\circ}$ ano (5MAT e 5VES) e 2 turmas do $7^{\circ}$ ano (7A/7B) do Ensino Fundamental da Escola Autonomia (www.autonomia.com.br) em Florianópolis/SC no primeiro semestre de 2015. A Escola Autonomia é uma escola privada, que oferece educação infantil, Ensino Fundamental e Ensino Médio. Participaram da aplicação um total de 105 alunos conforme detalhada a Tabela 3.

\begin{tabular}{c|l|c|c}
\hline Ano & Turma & $\begin{array}{c}\text { Quantidade } \\
\text { de alunos }\end{array}$ & $\begin{array}{c}\text { Média de professo- } \\
\text { res/auxiliares de } \\
\text { computação presen- } \\
\text { tes nos encontros }\end{array}$ \\
\hline $5^{\circ}$ Ano & $5 \mathrm{M}$ matutino & 24 & 4 \\
\hline $5^{\circ}$ Ano & $5 \mathrm{~V}$ vespertino & 21 & 1 \\
\hline $7^{\circ}$ Ano & $7 \mathrm{~A}$ matutino & 31 & 3 \\
\hline $7^{\circ}$ Ano & $7 \mathrm{~B}$ matutino & 29 & 1 \\
\hline
\end{tabular}

Tabela 3: Quantidade de alunos e instrutores de computação por turma.

As aulas foram ministradas pelo professor da disciplina de História da escola Autonomia em conjunto com professores e alunos de computação do Departamento de Informática e Estatística (INE) da UFSC, no âmbito da iniciativa Computação na Escola [22]. As aulas foram inseridas na carga horária da disciplina de História, presente no currículo escolar. Conforme apresentado na Tabela 3, as aulas foram ministradas bissemanalmente adaptando o cronograma às disponibilidades de cada turma.

Os alunos puderam formar equipes de dois ou três integrantes, para a realização das atividades. Seguindo o conteúdo abordado previamente nas aulas de História $\left(7^{\circ}\right.$ ano) e estudos sociais ( $5^{\circ}$ ano), os alunos do quinto ano desenvolveram jogos referentes à história/cultura de Santa Catarina e os alunos do sétimo ano referentes às Civilizações Antigas.

Como a escola não possui sala de informática, as aulas foram realizadas utilizando notebooks na sala de aula. Os notebooks possuem tela de 15 polegadas e mouses ópticos, sistema operacional Microsoft Windows, e o acesso às páginas da web é realizado utilizando os navegadores web Firefox e Chrome. $\mathrm{O}$ acesso à rede de internet é realizado através de uma rede sem fio, sendo configurada pelo técnico de informática da escola no início da aula, adicionando um ponto de acesso WiFi ao computador do professor e à rede cabeada. A sala de aula também dispõe de projetor multimídia e quadro branco.

Algumas atividades, incluindo auxílio na preparação do material didático e a gerência dos backups dos trabalhos dos alunos, foram realizadas por bolsistas de graduação do INE/UFSC.

Nas aulas foi utilizada a versão 4.37 do Scratch para

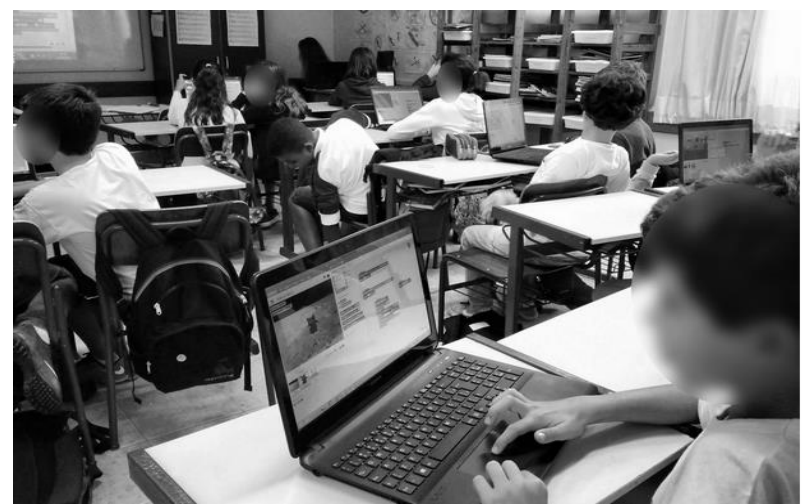

Figura 7: Alunos durante a unidade instrucional.

uso em navegadores web. Foi criada uma conta para cada equipe de alunos no site do Scratch e cada projeto foi identificado a partir de um nome escolhido pelos alunos. Foi criada também uma conta para gerenciar os projetos dos alunos, sendo que nessa conta foram criados quatro estúdios de compartilhamento $(5 \mathrm{M}, 5 \mathrm{~V}, 7 \mathrm{~A}, 7 \mathrm{~B})$ agregando todos os projetos de uma mesma turma no mesmo estúdio, possibilitando o compartilhamento dos trabalhos dos alunos.

As aulas foram realizadas conforme o plano de ensino. O professor da disciplina e os professores e alunos da computação forneceram assistência durante a realização da tarefa, enquanto os alunos desenvolviam os próprios jogos (vide Figura 7). Os resultados finais desenvolvidos pelos alunos durante o projeto foram compartilhados em estúdios no ambiente Scratch e podem ser encontrados no site:

http://www.computacaonaescola.ufsc.br/?page_id=203.

\section{Avaliação da unidade instrucional}

\subsection{Definição do estudo}

O objetivo do estudo, especificamente, consiste em explorar e compreender aspectos relacionados a unidades instrucionais para o ensino de conceitos de computação no Ensino Fundamental de forma multidisciplinar em disciplinas de História.

Para verificar se os objetivos de aprendizagem da unidade instrucional são atingidos, é definido um plano de medição seguindo a abordagem GQM [18], decompondo os objetivos em perguntas de análise e medidas, as quais são aplicadas por meio de questionários.

Conforme indicado na Figura 2, é realizado um estudo de caso com medição antes e após a unidade instrucional capturando a percepção dos alunos coletando dados via questionário. Após a unidade instrucional é levantada também a percepção dos pais sobre o impacto da unidade instrucional aos seus filhos e uma avaliação dos instruto- 
res em relação da unidade instrucional e seu impacto aos alunos da sua disciplina. Ao final da unidade instrucional também são analisados os jogos desenvolvidos pelos alunos representando resultados da aprendizagem.

\begin{tabular}{|c|c|c|}
\hline $\begin{array}{l}\text { Pergunta de } \\
\text { análise }\end{array}$ & Medida(s) & $\begin{array}{l}\text { Instrumento de } \\
\text { coleta de dados }\end{array}$ \\
\hline $\begin{array}{l}\text { PA1. } \\
\text { Os objetivos de } \\
\text { aprendizagem } \\
\text { (tanto em } \\
\text { relação à com- } \\
\text { putação quanto } \\
\text { à História) são } \\
\text { atingidos usan- } \\
\text { do a unidade } \\
\text { instrucional? }\end{array}$ & $\begin{array}{l}\text { M1.1 Grau de aprendiza- } \\
\text { gem referente à capacidade } \\
\text { de fazer programas de } \\
\text { computador. } \\
\text { M1.2 Grau de aprendizagem } \\
\text { referente à capacidade de } \\
\text { descrever, analisar e pro- } \\
\text { gramar uma sequência de } \\
\text { instruções a ser seguida. } \\
\text { M1.3 Grau de aprendizagem } \\
\text { referente à capacidade do } \\
\text { uso do ambiente Scratch } \\
\text { para criar e desenvolver um } \\
\text { jogo em grupo dentro do } \\
\text { ambiente, comparti- } \\
\text { lhar/publicar e comentar } \\
\text { outros jogos. } \\
\text { M1.4 Grau de habilidade } \\
\text { para ensinar o aprendido a } \\
\text { outras pessoas. }\end{array}$ & $\begin{array}{l}\text { - Rubrica } \\
\text { - Questionário } \\
\text { aluno pré/pós- } \\
\text { unidade } \\
\text { - Questionário } \\
\text { instrutor pós- } \\
\text { unidade } \\
\text { - Ambiente de } \\
\text { programação } \\
\text { Scratch } \\
\text { - Ferramenta de } \\
\text { avaliação Dr. } \\
\text { Scratch } \\
\text { - Observações } \\
\text { durante as aulas }\end{array}$ \\
\hline $\begin{array}{l}\text { PA2. } \\
\text { A unidade } \\
\text { instrucional } \\
\text { facilita a apren- } \\
\text { dizagem? }\end{array}$ & $\begin{array}{l}\text { M2.1. Grau de facilidade das } \\
\text { aulas. } \\
\text { M2.2. Grau de facilidade de } \\
\text { fazer programas de compu- } \\
\text { tador. } \\
\text { M2.3. Grau da qualidade } \\
\text { geral das aulas. } \\
\text { M2.4 Pontos fortes em } \\
\text { relação à facilidade das } \\
\text { aulas. } \\
\text { M2.5 Pontos fracos em } \\
\text { relação à dificuldade das } \\
\text { aulas. }\end{array}$ & $\begin{array}{l}\text { - Questionário } \\
\text { aluno pós- } \\
\text { unidade } \\
\text { - Observações } \\
\text { durante as aulas }\end{array}$ \\
\hline $\begin{array}{l}\text { PA3. } \\
\text { A unidade } \\
\text { instrucional } \\
\text { promove uma } \\
\text { experiência de } \\
\text { aprendizagem } \\
\text { agradável e } \\
\text { divertida? }\end{array}$ & $\begin{array}{l}\text { M3.1 Grau da diversão das } \\
\text { aulas. } \\
\text { M3.2 Grau da imersão das } \\
\text { aulas. } \\
\text { M3.3 Grau da interação } \\
\text { social (querer mostrar aos } \\
\text { outros). } \\
\text { M3.4 Opinião subjetiva } \\
\text { sobre as aulas. } \\
\text { M3.5 Pontos fortes em } \\
\text { relação à experiência das } \\
\text { aulas. } \\
\text { M3.6 Pontos fracos em } \\
\text { relação à experiência das } \\
\text { aulas. }\end{array}$ & $\begin{array}{l}\text { - Questionário } \\
\text { aluno pós- } \\
\text { unidade. } \\
\text { - Observações } \\
\text { durante as aulas }\end{array}$ \\
\hline $\begin{array}{l}\text { PA4. } \\
\text { A unidade } \\
\text { instrucional } \\
\text { proporciona }\end{array}$ & $\begin{array}{l}\text { M4.1. Vontade de aprender } \\
\text { computação na escola } \\
\text { M4.2. Grau de satisfação em } \\
\text { fazer programas de compu- }\end{array}$ & $\begin{array}{l}\text { - Questionário } \\
\text { aluno pré/pós- } \\
\text { unidade } \\
\text { - Observações }\end{array}$ \\
\hline
\end{tabular}

\begin{tabular}{|c|c|c|}
\hline $\begin{array}{l}\text { uma percepção } \\
\text { positiva da } \\
\text { computação? }\end{array}$ & $\begin{array}{l}\text { tador. } \\
\text { M4.3 Grau de diversão em } \\
\text { fazer programas de compu- } \\
\text { tador. }\end{array}$ & $\begin{array}{l}\text { durante as aulas } \\
\text { - Questionário } \\
\text { instrutor pós- } \\
\text { unidade }\end{array}$ \\
\hline
\end{tabular}

Tabela 4: Definição do plano de medição.

Esses procedimentos de pesquisa foram aprovados pelo CEPSH - Comitê de Ética em Pesquisa com Seres Humanos da UFSC, conforme parecer nro. 1.021.541.

\subsection{Coleta de dados}

A avaliação foi realizada conforme previamente definida (vide Seção 3) com dados coletados via questionários dos alunos e do professor, além das observações dos instrutores e professores envolvidos e com base na análise dos resultados produzidos pelos alunos. A Tabela 5 apresenta um resumo dos dados coletados durante o estudo.

\begin{tabular}{c|c|c|c}
\hline Ano & $\begin{array}{c}\text { Quantidade de } \\
\text { questionários } \\
\text { respondidos } \\
\text { pré/pós unidade } \\
\text { aluno }\end{array}$ & $\begin{array}{c}\text { Quantidade de } \\
\text { questionários } \\
\text { respondido pelo } \\
\text { professor da } \\
\text { disciplina }\end{array}$ & $\begin{array}{c}\text { Quantidade } \\
\text { de jogos } \\
\text { criados }\end{array}$ \\
\hline 5. Ano & $45 / 45$ & 1 & 18 \\
\hline 7. Ano & $60 / 54$ & 1 & 23 \\
\hline
\end{tabular}

Tabela 5: Resumo dos dados coletados.

\subsection{Análise dos dados}

Os dados coletados via questionários e observações foram analisados por meio de análises qualitativas e quantitativas utilizando estatística descritiva. Os resultados produzidos pelos alunos foram analisados utilizando a ferramenta on-line Dr. Scratch [21]. Dr. Scratch é uma ferramenta de análise para avaliar projetos em vários aspectos relacionados a conceitos de programação e pensamento computacional.

Observando os alunos durante as aulas foi possível perceber que, em geral, todas as equipes conseguiram criar um jogo, sendo que a maioria dos alunos participou ativamente das seis aulas, programando no ambiente Scratch, demonstrando entusiasmo e vontade de trabalhar no ambiente. Focando nos temas multidisciplinares, os alunos utilizaram atores e cenários no contexto da disciplina de História. Os personagens relacionados ao tema de história (romanos, gregos, índios, etc.) assim como os cenários dos jogos foram escolhidos dentro da própria biblioteca de imagens do Scratch, ou em buscadores de imagens como Google Imagens (http://images.google.com.br) e Bing (http://www.bing.com.br) ou, foram desenhados dentro da própria ferramenta de desenho do Scratch. Foram criados também roteiros para cada ator, tais como: falar, andar, fazer perguntas, pular, desaparecer, reaparecer, trocar cenários e ou fantasia etc. Os alunos, em geral, 
optaram por fazer jogos do tipo ação, quiz e aventura conforme a Tabela 6 .

Para classificar os jogos dos alunos, foi adotado o sistema de Herz [23], o qual é parecido com o utilizado pelas indústrias de jogos em geral. Em alguns jogos pôdese observar a presença de alguns elementos comumente encontrados em outros gêneros/subgêneros diferentes do escolhido, tornando-os híbridos. Contudo, para fins de avaliação e estatísticos, os jogos foram classificados somente pelo seu principal gênero. No total, foram desenvolvidos 41 jogos pelos alunos.

\begin{tabular}{l|l|c}
\hline \multicolumn{1}{c|}{ Gênero } & \multicolumn{1}{c|}{ Descrição } & Jogos criados \\
\hline Ação & $\begin{array}{l}\text { Jogos que dão ênfase aos movimen- } \\
\text { tos, normalmente são baseados em } \\
\text { reações. }\end{array}$ & 13 \\
\hline Quiz & $\begin{array}{l}\text { O jogador precisa responder per- } \\
\text { guntas para uma determinada área } \\
\text { de conhecimento. }\end{array}$ & 12 \\
\hline Aventura & $\begin{array}{l}\text { Jogos focados no enredo onde o } \\
\text { jogador acompanha uma história } \\
\text { por meio de tex- } \\
\text { tos/músicas/imagens, podem incluir } \\
\text { quebra-cabeças. }\end{array}$ & 5 \\
\hline $\begin{array}{l}\text { Sem gênero } \\
\text { ou jogo } \\
\text { incompleto }\end{array}$ & $\begin{array}{l}\text { O jogo não possui um gênero claro } \\
\text { ou não está terminado. }\end{array}$ & \\
\hline
\end{tabular}

Tabela 6: Distribuição dos gêneros de jogos feitos pelos alunos.

Para detalhar melhor os resultados obtidos, são apresentando em seguida os resultados para cada pergunta de análise.

\subsection{Os objetivos de aprendizagem da unidade instrucional foram atingidos?}

Para analisar se os objetivos de aprendizagem definidos foram atingidos, foi realizada uma análise detalhada dos jogos criados e das observações feitas durante as aulas de acordo com os objetivos de aprendizagem definidos (Tabela 7).

\begin{tabular}{l|l}
\hline \multicolumn{1}{c|}{ Análise } & \multicolumn{1}{c}{ Objetivos } \\
\hline $\begin{array}{l}\text { Todos os } \\
\text { alunos } \\
\text { atingiram o } \\
\text { objetivo. }\end{array}$ & $\begin{array}{l}\text { [OC1] Usar os passos básicos da solução de proble- } \\
\text { mas algorítmicos/engenharia de software para projetar } \\
\text { resoluções de problemas. } \\
{[\mathrm{OC} 2] \text { Descrever e analisar uma sequência de instru- }} \\
\text { ções a ser seguida. }\end{array}$ \\
\hline $\begin{array}{l}\text { A maioria } \\
\text { dos alunos } \\
\text { atingiu o } \\
\text { objetivo. }\end{array}$ & $\begin{array}{l}\text { [OC3] Entender e aplicar conceitos de programação. } \\
\text { ver e compartilhar um jogo de história. } \\
{[\text { OC5] Colaborativamente criar, desenvolver, publicar }} \\
\text { e apresentar produtos usando recursos tecnológicos } \\
\text { que demonstram e comunicam conceitos do currículo. } \\
{[\text { OH1] Demonstrar conhecimento sobre o modo de }}\end{array}$ \\
\hline
\end{tabular}

\begin{tabular}{l|l}
\hline & $\begin{array}{l}\text { vida de diferentes grupos, em diversos tempos e } \\
\text { espaços, em suas manifestações culturais e sociais, } \\
\text { reconhecendo semelhanças e diferenças entre eles e } \\
\text { seus conflitos. } \\
{[\mathrm{OH} 2] \text { Utilizar fontes históricas em suas pesquisas }} \\
\text { escolares. }\end{array}$ \\
\hline $\begin{array}{l}\text { A minoria } \\
\text { atingiu o } \\
\text { objetivo. }\end{array}$ & - \\
\hline $\begin{array}{l}\text { Nenhum } \\
\text { aluno } \\
\text { atingiu o } \\
\text { objetivo. }\end{array}$ & - \\
\hline
\end{tabular}

Tabela 7: Análise do atendimento de objetivos de aprendizagem.

Todos os alunos conseguiram utilizar com facilidade o ambiente Scratch para a programação de um jogo. Os grupos conseguiram utilizar passos básicos para a criação de diálogos, sincronização de eventos do jogo e movimentação de personagens. Os grupos realizaram a concepção de um jogo fazendo uso principalmente da abstração. Após o debate de como seria o jogo, os alunos conseguiram decompor ideias mais complexas em várias ideias mais simples. Isto lhes permitiu fazer a construção passo a passo de funções mais complicadas.

Dentro do ambiente Scratch praticamente todos os alunos utilizaram comandos de modificar a aparência e o plano de fundo, criando um estilo diferente para cada projeto. Isto pode ser visto com mais detalhes na análise de quais conceitos foram implementados nos jogos (Figura 8). Os jogos foram analisados contabilizando os comandos utilizados na implementação dos jogos por meio da ferramenta Dr. Scratch.

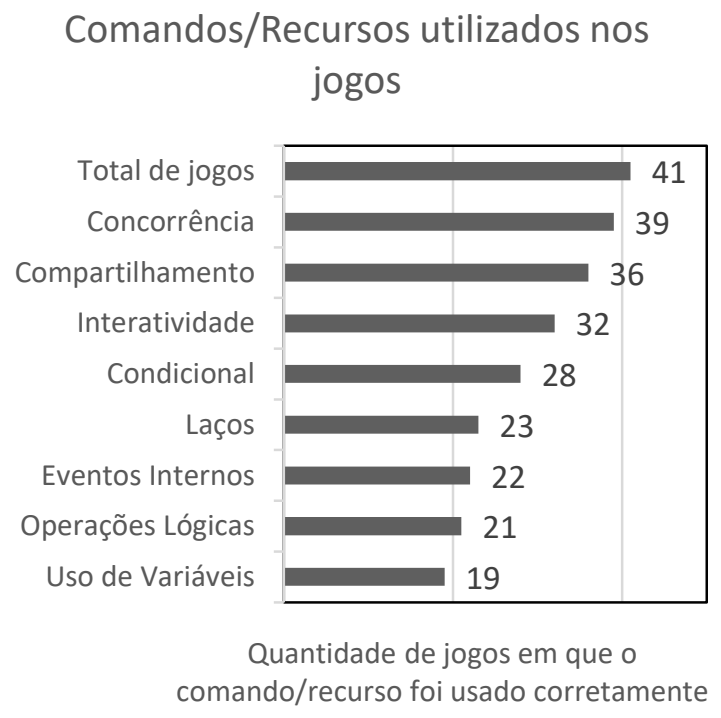

Figura 8: Contabilização da utilização de comandos/recursos. 
Os resultados observados indicam que os alunos utilizaram em grande parte o conceito de condicional, concorrência e interatividade. Os comandos do tipo condicional foram utilizados na maioria para auxiliar mudanças de aparência, plano de fundo e ganho de pontuação.

$O$ recurso de concorrência foi explorado devido ao fato de que em quase todos os jogos tinha-se mais de um personagem e assim foi necessário programar ações concorrentes para cada um destes personagens. Assim, foram programados vários scripts para serem executados ao mesmo tempo, devido à quantidade de personagens e a necessidade de sincronização entre eles. Por exemplo, a conversa entre dois personagens dentro do jogo foi implementada na maioria dos jogos, onde se faz necessário o controle sobre qual personagem deve falar em determinado momento.

A interatividade foi usada principalmente para a movimentação dos personagens e para a possibilidade de responder perguntas nos jogos do gênero quiz pelos jogadores. Os alunos também fizeram a interatividade com o jogador, através do teclado, como por exemplo, utilizando setas para andar/pular.

Os demais recursos como laços, eventos internos, operações lógicas e uso de variáveis foram utilizados por uma parte dos alunos. Isto decorre da não utilização em jogos do gênero aventura, que são focados no enredo, onde o jogador acompanha por meio de textos, imagens e músicas.

Os laços foram utilizados pelos alunos quando percebiam que estavam repetindo várias vezes certos blocos de comandos para realização de certas funções. Alguns alunos utilizaram eventos internos em conjunto com a concorrência para a sincronização dos personagens. Em alguns jogos, também foi adicionado um sistema de pontuação através do uso de operações lógicas e variáveis, onde o jogador pode acumular certa quantidade de pontos dependendo do tipo de ação que executou.

Esses dados indicam que houve aprendizagem eficaz de conceitos de programação. Os alunos tiveram contato e usaram desde conceitos simples, como operações lógicas, até conceitos mais avançados como sincronização.

Este efeito da aprendizagem também é percebido na autoavaliação dos alunos. Após a unidade instrucional, a maioria dos alunos indica que consegue fazer programas de computador. Porém, somente uma parte dos alunos considera que atingiu níveis mais altos de aprendizagem na programação (p.ex. concordando que conseguem explicar para algum colega como fazer um programa) (vide Figura 9 e Figura 10).

Referente à colaboração, foi possível observar que a possibilidade de escolher o gênero e como seria concebido o jogo estimulou o debate e a contribuição de ideias

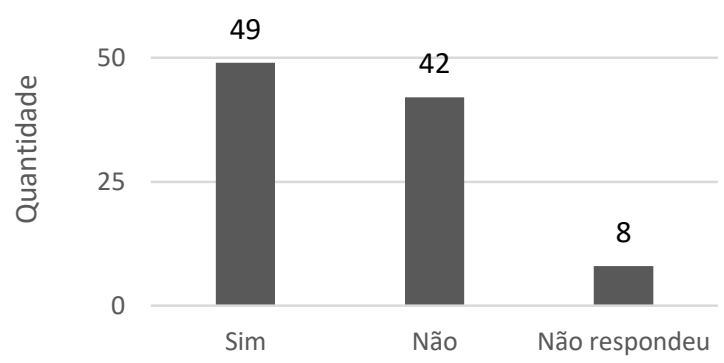

Figura 9: "Eu consigo explicar para um amigo(a) como fazer um programa de computador" dados após a aplicação.

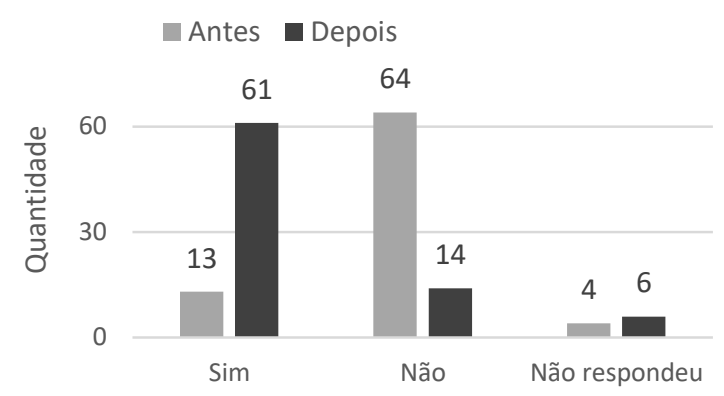

Figura 10: "Eu consigo fazer programas de computador" dados de antes e depois da aplicação.

pela maioria dos integrantes dos grupos. Entretanto, poucos alunos não conseguiram concordar e avançar em certas decisões sobre o jogo, o que pode ter ocorrido em razão de diferentes ideias não serem aceitas e ou compartilhadas pelos demais colegas. Foi possível observar também que alguns alunos dispersaram quando determinadas atividades envolvendo decisões sobre o jogo deveriam ser realizadas. Apesar disso, ao conseguirem implementar uma função mais complexa de forma efetiva, os alunos mostravam e compartilhavam o que e como haviam feito.

Isso teve um efeito motivador sobre os demais que em seguida começavam a fazer algo derivado ou aplicavam ideias utilizadas pelos colegas para solucionarem problemas bastante diferentes dos seus jogos, apoiados pela assistência dos professores e instrutores.

Em relação à disciplina de História/estudos sociais, a maioria dos alunos conseguiu desenvolver um jogo com o tema proposto em sala (civilizações da história antiga europeia e história de Santa Catarina). Os alunos consultaram materiais didáticos, anotações feitas em aulas anteriores e ferramentas de busca on-line para pesquisas sob a orientação do professor de História em sala. 
Nos $5^{\circ}$ anos a maior parte dos jogos focou nas primeiros povoadores de Santa Catarina: os sambaquis; os guarani; os xokleng; os kaigang. Desta forma, os alunos conseguiram desenvolver suas concepções de história ao colocar os grupos indígenas como protagonistas dos jogos. Em outros há o encontro entre os europeus colonizadores e os grupos originários. Há ainda, outros jogos que tratam de conceitos da parte da geografia do Estado de Santa Catarina, já que a proposta da disciplina de estudos sociais é trabalhar simultaneamente as disciplinas de História e Geografia. Os alunos conseguiram, a sua maneira, construir o seu conhecimento histórico.

No $7^{\circ}$ anos, os alunos conseguiram trabalhar vários conceitos que compreendem a história antiga europeia, focando nas civilizações Gregas e Romanas. Além de jogos focados nas olimpíadas, ou de gladiadores no Coliseu, os alunos construíram também narrativas que recontavam a história das origens de Roma até as expansões do império, e em outras narrativas acompanhamos a vista de um contemporâneo ao passado.

Nestas perspectivas podemos verificar que o conhecimento histórico, tanto nos $5^{\circ}$ anos como nos $7^{\circ}$ anos, foram contemplados em uma perspectiva cronológica circular, onde se faz os questionamentos no presente, representa-se o passado, e seu resultado é posto novamente no presente em forma de um produto final [24].

$\mathrm{O}$ que podemos inferir que os alunos conseguiram articular conceitos como espaço, tempo, cultura, sociedade mesclando problematizações macro e micro em seus produtos finais. Podemos ver que as concepções de história dos alunos transitou entre um conhecimento escolar $\mathrm{e}$ um outro viabilizado pelo uso do Scratch, que fez com que os alunos apreendessem a história de outro ponto de vista: como produtores de conhecimento histórico.

\subsection{A unidade instrucional facilita a aprendi- zagem?}

A maioria dos alunos achou as aulas muito fáceis ou fáceis. Poucos alunos consideraram as aulas difíceis e somente um aluno achou muito difícil. Isso, mesmo que em geral, os alunos consideram a programação em si não tão fácil (vide Figura 11 e 12).

Os comentários qualitativos referentes as aulas também indicam esse resultado (Tabela 8). Em algumas respostas, também foi destacado que apesar de se ter dificuldades, em certos momentos, os alunos acharam as aulas fáceis. Em geral, percebeu-se que os alunos utilizaram com facilidade os recursos de programação do ambiente Scratch. A variedade de personagens, diálogos e ações nos jogos, mostra que os alunos aprenderam a usar e adaptar os recursos do Scratch. Muitos dos alunos aprenderam a utilizar funções do ambiente Scratch sem instrução de professor ou assistente. Observou-se que a possibilidade de execução do código e visualização dentro do próprio ambiente, facilitou aos alunos encontrar

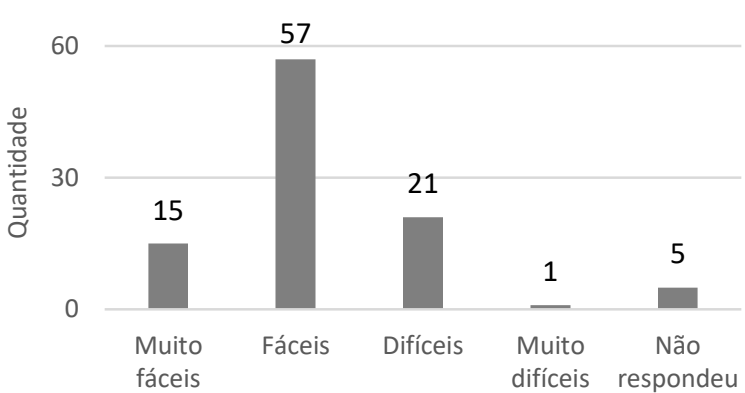

Figura 11: "As aulas foram?"

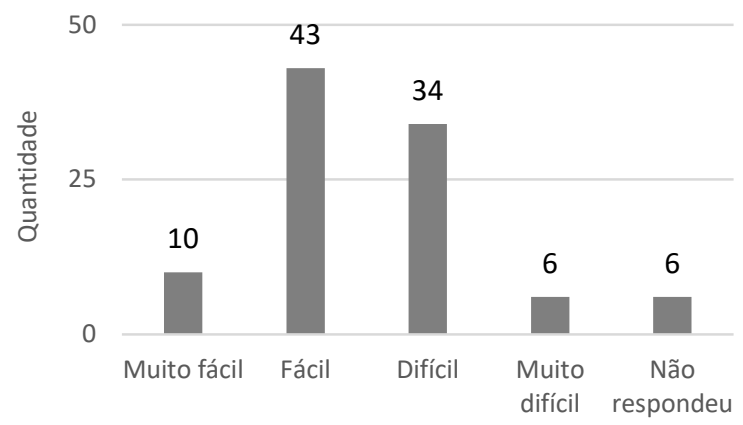

Figura 12: "Fazer programas de computador é?".

erros simples de forma rápida e imediatamente corrigilos.

Foi mencionada também a complexidade/dificuldade para programar os jogos, ou ainda, quando não se sabia a priori como programar certas funções. Isto pode ter ocorrido devido a alguns grupos na hora da implementação, começarem por funções avançadas, antes de funções mais simples. As respostas também indicam que vários alunos acharam a questão do compartilhamento complicada. Na hora da criação da conta, alguns alunos também tiveram dificuldades pois após colocarem todos os dados, o Scratch reportava um erro desconhecido. Contudo, após algumas tentativas os alunos conseguiram realizar a criação de conta.

É interessante observar que muitos alunos tiveram dificuldades devido à necessidade de confirmação de email no momento do cadastro no site do Scratch para permitir a ativação da conta. Essa dificuldade ocorreu especialmente com os alunos que utilizaram o e-mail dos pais na hora da criação de conta no Scratch pois não possuíam e-mail próprio. Assim, era necessário entrar no e-mail e confirmar a ativação de conta, caso contrário o Scratch não permitia o compartilhamento de um projeto. Alguns alunos ficaram confusos, pois o Scratch permite criar/excluir projetos, entre outras funções, sem a necessidade de confirmação, contudo, o compartilhamento necessita especificamente dessa confirmação. Isto foi solucionado pelos alunos que pediram aos pais em casa para ativarem suas contas no Scratch pelo e-mail. 
Parte dos alunos preferiu utilizar o software do MIT Scratch 2.0 (off-line) ao invés do ambiente on-line. Isto ocorreu devido às instabilidades da rede na escola, o que tornava difícil salvar avanços feitos de tempos em tempos.

\begin{tabular}{|c|c|}
\hline Tópico & Comentários \\
\hline \multirow{8}{*}{$\begin{array}{l}\text { Facilidade } \\
\text { das aulas }\end{array}$} & "Muito legais, divertidas e fáceis." \\
\hline & "Ótimas, fáceis e divertidas." \\
\hline & $\begin{array}{l}\text { "Legal, achei divertido criar um jogo e testar outros } \\
\text { jogos, apesar de alguns momentos ter uma dificuldade." }\end{array}$ \\
\hline & $\begin{array}{l}\text { "Adorei! Não fazia ideia de como computação é diver- } \\
\text { tida e não necessariamente tão difícil." }\end{array}$ \\
\hline & $\begin{array}{l}\text { "Achei as aulas divertidas e educativas, porém não } \\
\text { consegui aprender muito." }\end{array}$ \\
\hline & $\begin{array}{l}\text { "Eu achei bem interessante, mesmo tendo alguns } \\
\text { problemas." }\end{array}$ \\
\hline & "Complicadas." \\
\hline & "Muito complicadas, com o prazo curto." \\
\hline \multirow{5}{*}{$\begin{array}{l}\text { Pontos } \\
\text { fortes em } \\
\text { relação à } \\
\text { facilidade }\end{array}$} & "Conseguir superar os objetivos." \\
\hline & "Quando eu sabia fazer as coisas." \\
\hline & "Os desafios." \\
\hline & $\begin{array}{l}\text { "Quando eu conseguia programar alguma coisa que } \\
\text { desse certo e ficasse legal." }\end{array}$ \\
\hline & "O método de aprendizagem." \\
\hline \multirow{6}{*}{$\begin{array}{l}\text { Pontos } \\
\text { fracos em } \\
\text { relação à } \\
\text { facilidade }\end{array}$} & "Quando eu não sabia fazer as coisas." \\
\hline & $\begin{array}{l}\text { "Quando eu ficava frustrada por minhas programa- } \\
\text { ções não derem certo." }\end{array}$ \\
\hline & $\begin{array}{l}\text { "A dificuldade de fazer os comandos, não entendi } \\
\text { muito bem como se faz." }\end{array}$ \\
\hline & "Dificuldades dos jogos." \\
\hline & "Compartilhar, achei muito complicado." \\
\hline & $\begin{array}{l}\text { "Muito complicado para compartilhar o jogo feito, } \\
\text { travava, não mandava, não entrava." }\end{array}$ \\
\hline
\end{tabular}

Tabela 8: Respostas discursivas dos alunos no questionário pós-unidade referente às facilidades.

\subsection{A unidade instrucional promove uma experiência de usuário agradável e diver- tida?}

Segundo as respostas dos alunos, as aulas foram avaliadas pela maioria de forma positiva como muito divertidas/divertidas e excelentes/boas. Poucos alunos avaliaram as aulas de forma negativa, conforme pode ser observado na Figura 13 e 14.

Esta percepção positiva das aulas também se reflete na percepção dos alunos em relação ao tempo das aulas, em que a maioria indica que as aulas para eles passaram muito rápido/rápido (Figura 15). As respostas positivas estão relacionadas aos alunos que conseguiram fazer avanços significativos dos seus projetos na maioria das aulas e que conseguiram ter uma boa interação entre os colegas.

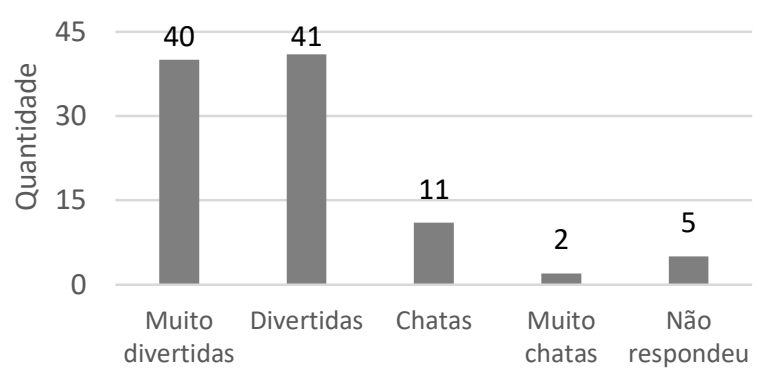

Figura 13: "As aulas foram?"

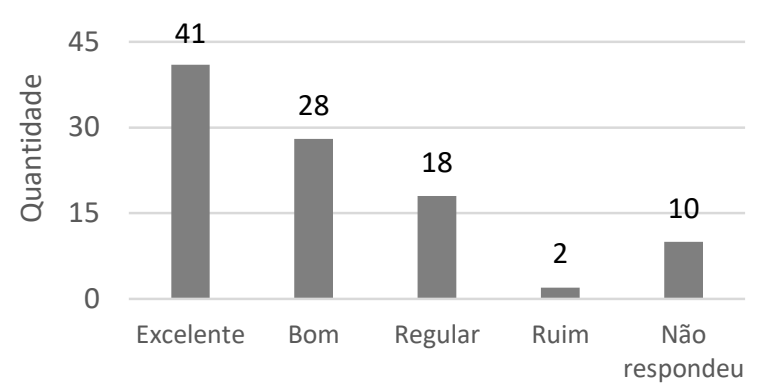

Figura 14: "As aulas foram?"

Uma das razões da percepção negativa pode ser pelas dificuldades encontrados durante as aulas em relação a infraestrutura. Alguns dos problemas foram a instabilidade da rede na escola e o descarregamento de baterias de notebooks. Com relação à rede e às baterias, estes problemas ocorreram porque a escola não dispõe de um laboratório de computadores, assim, eram trazidos notebooks para a sala que às vezes estavam apenas parcialmente carregados e os alunos tinham que trocar de máquina depois de um certo tempo.

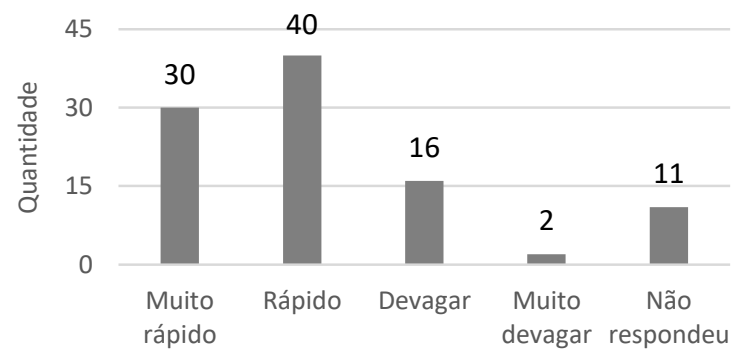

Figura 15: "O tempo das aulas passou?".

A instabilidade da rede não permitiu que os alunos salvassem os avanços feitos no projeto e alguns grupos nas aulas seguintes reprogramavam funções que já haviam feito na aula anterior. Como algumas aulas foram ministradas somente pelo professor da disciplina sem auxílio de monitores, os alunos indicaram também como problema a quantidade insuficiente de instrutores para 
atendimento de dúvidas de todos os grupos naquelas aulas.

Entretanto, em geral, os alunos tiveram uma boa experiência durante as aulas (Tabela 9). A possibilidade de criar personagens e escolher os gêneros de cada jogo de forma livre foi apontada pelos alunos como sendo divertida. Apesar de alguns alunos acharem que tiveram tempo de mais, os alunos em geral gostariam de ter mais aulas e com mais frequência.

Isto também foi percebido pelo professor da disciplina de História, o qual observou que os alunos gostavam de ir às aulas para fazer programas de computador, e que eles gostavam de mostrar aos colegas e monitores quando conseguiam implementar algo com sucesso.

$\mathrm{O}$ que foi mais criticado pelos alunos referente à experiência, estava relacionado principalmente à infraestrutura da escola e a quantidade de pessoas disponíveis para atender as dúvidas. Nas aulas em que se faziam presentes mais de 3 professores e monitores, os alunos conseguiam avançar significativamente e demonstravam mais satisfação.

No último dia os alunos demonstraram bastante entusiasmo quando puderam verificar o resultado de semanas de trabalho, jogar os jogos programados pelos colegas e dizer o que acharam de cada jogo, dando sugestões e fazendo críticas. Muitos alunos gostariam que as aulas tivessem durado mais tempo, inclusive alguns queriam que o projeto se estendesse até o final do ano. A maioria também achou que as aulas deveriam ocorrer com mais frequência.

\begin{tabular}{c|l}
\hline \multicolumn{1}{c|}{ Tópico } & \multicolumn{1}{c}{ Comentários } \\
\hline $\begin{array}{l}\text { Experiência } \\
\text { das aulas }\end{array}$ & $\begin{array}{l}\text { "Eu achei que estas aulas foram incríveis!" } \\
\text { "Adorei! Não fazia ideia de como computação é } \\
\text { "Eu achei uma ótima aula de muita aprendizagem, } \\
\text { diversão e interesse." } \\
\text { "Achei que foi uma experiência única e agradável." } \\
\text { "Muito complicadas, com o prazo curto." } \\
\text { "Eu achei interessante e legal mas é pouco tempo." } \\
\text { "Eu achei muito legal nós fazermos esse trabalho com } \\
\text { o Scratch porque nós aprendemos um pouco como é } \\
\text { um trabalho com computação, e espero ter mais aulas } \\
\text { assim." } \\
\text { "Eu achei muito legal, divertido e espetacular! Gostei } \\
\text { muito de ter aprendido isso! O Scratch é demais." } \\
\text { "Eu achei legal, mas achei que os monitores poderiam } \\
\text { dar mais atenção." } \\
\text { "Eu fiquei um pouco entediado com essas aulas e com } \\
\text { dor de cabeça também." } \\
\text { "As aulas são chatas, e eu não gostei." } \\
\text { "Foi de criar o jogo foi muito legal mesmo." } \\
\text { "Tudo, principalmente criar os personagens." }\end{array}$ \\
\hline
\end{tabular}

\begin{tabular}{l|l}
\hline & $\begin{array}{l}\text { histórias." } \\
\text { "Que nós aprendemos a fazer jogos e trabalhamos } \\
\text { com a computação um pouco mais elaborada." } \\
\text { "Poder aprender a mexer no Scratch, fazer o trabalho } \\
\text { bem legal." } \\
\text { "Gostei de aprender como usar o Scratch, já que } \\
\text { nunca tinha usado." } \\
\text { "O tempo = bastante. O site, o que dava para fazer no } \\
\text { mesmo." } \\
\text { "Fazer o jogo com os meus amigos." } \\
\text { "O resultado dos jogos." } \\
\text { "Na última aula que foi quando nós jogamos os } \\
\text { próprios jogos." }\end{array}$ \\
\hline $\begin{array}{l}\text { Pontos } \\
\text { fracos em } \\
\text { elação à } \\
\text { experiência pessoas que tinham que ajudar não me ouviram." } \\
\text { "Nós demorávamos para receber ajuda." } \\
\text { "O que menos gostei foi que as aulas passavam muito } \\
\text { rápido e que era somente } 1 \text { aula a cada 15 dias." } \\
\text { "Que não foram todas as semanas." } \\
\text { "De ter que refazer } 8 \text { vezes o jogo no Scratch." } \\
\text { "Foi que todos os computadores acabavam a bateria } \\
\text { bem na minha vez." } \\
\text { "Tem muito poucas aulas." } \\
\text { "O número grande de aulas até a apresentação final." } \\
\text { "Ter que dividir 1 computador.” }\end{array}$ \\
\hline
\end{tabular}

Tabela 9: Respostas discursivas dos alunos no questionário pós-unidade referente à experiência.

\subsection{A unidade instrucional motiva os alunos a aprender computação?}

Percebeu-se que durante e após o final da unidade instrucional grande parte dos alunos demonstraram vontade de continuar programando com Scratch. Isso também foi percebido pelo professor da disciplina que observou que muitos dos alunos gostaram de fazer programas de computador (Figura 16).

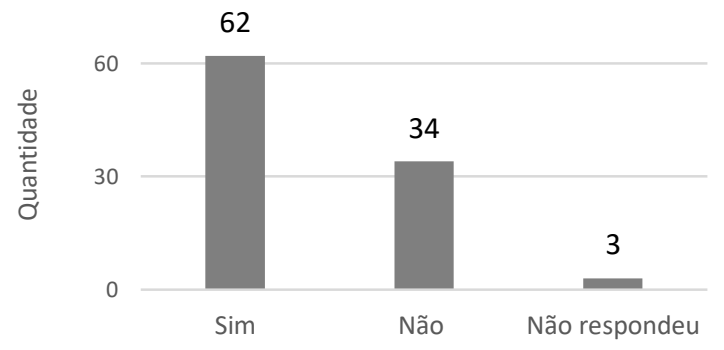

Figura 16: "Quero aprender mais sobre como fazer programas de computador".

A capacidade de resolver algo que parecia impossível a princípio foi apontada por muitos alunos como sendo uma das características mais motivadoras do projeto. Os alunos trocaram bastante ideias entre si, mostrando aos colegas sempre que implementavam uma nova função no jogo. Isto manteve grande parte dos alunos motivados 
para concluir o projeto.

Alguns pais também observaram que a mudança de foco de jogar um jogo educacional para a criação do jogo em si, foi o que mais motivou seus filhos. $O$ fato do jogo ser inteiramente feito por eles, e no final poderem jogar seus próprios jogos, conferiu uma sensação de autonomia e capacidade às crianças.

\subsection{Ameaças à validade}

Existem diversos fatores no design da pesquisa que podem ter influenciado a validade dos resultados. Uma das ameaças é relacionada à forma de medir os objetivos de avaliação. Para diminuir erros de medição foi adotada a abordagem GQM [18], que auxilia na decomposição sistemática dos objetivos de medição.

Em relação à coleta de dados, para minimizar possíveis ameaças à validade, os questionários foram projetados e revisados coletivamente com cuidado, tentando usar uma linguagem fácil de entender que permitiria aos envolvidos responderem os questionários corretamente de acordo com a sua faixa etária.

Ao final, obteve-se uma amostra de tamanho aceitável (total de 105 alunos), apesar de alguns alunos terem respondido apenas um dos questionários pré/pós. Porém, para analisar melhor a generalizabilidade dos resultados obtidos será necessária a repetição do estudo em outras escolas. Mesmo assim, foi possível obter um primeiro feedback significativo referente à aplicação da unidade instrucional no contexto de uma pesquisa exploratória.

\section{Conclusão}

O presente trabalho mostra uma primeira indicação de que o ensino de computação usando Scratch pode ser adotado com sucesso já no Ensino Fundamental de forma multidisciplinar. Em geral, foi possível observar que a unidade instrucional permitiu o ensino e aprendizagem de vários conceitos de computação, incluindo principalmente a programação e o pensamento computacional além de reforçar as competências referentes à disciplina de História, comparando aspectos culturais e políticos de diferentes épocas. Foi observado também, que as aulas motivaram os alunos a aprender mais sobre coisas novas e promoveram uma experiência de aprendizagem agradável e satisfatória para os alunos.

Este estudo de caso também forneceu um feedback significativo referente ao design instrucional e à sua estrutura e organização. A partir deste feedback a unidade instrucional está sendo revisada e melhorada no contexto da iniciativa Computação na Escola, com o objetivo de ampliar o ensino de computação nas escolas brasileiras.

\section{Agradecimentos}

Este trabalho foi financiado pelo CNPq (Conselho Nacional de Desenvolvimento Científico e Tecnológico), uma entidade do governo brasileiro focado no desenvolvimento científico e tecnológico e pelo Programa da Iniciação à Pesquisa Institucional (PIBIC/UFSC).

Gostaríamos agradecer as Coordenadoras Pedagógicas dos $5^{\circ}$ anos Barbara Giese e Angela Duarte, a Coordenadora dos $7^{\circ}$ anos Adriana Ramos e a Diretora Pedagógica Eloiza Schumacher Corrêa da Escola Autonomia pela oportunidade da realização do estudo de caso.

\section{Referências}

[1] CSTA. K-12 Computer Science Standards. The CSTA Standards Task Force. CSTA K-12 Computer Science Standards, ACM, New York/USA, 2011.

[2] H. S. Lin. Technology Everywhere A Campus Agenda for Educating and Managing Workers in the Digital Age. IT Fluency: What Is It, and Why Do We Need It? EDUCAUSE, 2005.

[3] Code.org. Disponível em: <http://code.org $>$. Acesso em: mar. 2016.

[4] MIT. SCRATCH, 2016 Disponível em http://scratch.mit.edu Acesso em: mar. 2016.

[5] PCN, Parâmetros Curriculares Nacionais, Terceiro e Quarto ciclos do Ensino Fundamental. MEC. Disponível em:

$<$ http://portal.mec.gov.br/seb/arquivos/pdf/introdu cao.pdf $>$. Acesso em: mar. 2016.

[6] GOOGLE, Searching for Computer Science: Access and Barriers in U.S. K-12 Education. Disponível em:

$<$ http://services.google.com/fh/files/misc/searchin g-forcomputer-science_report.pdf $>$. Acesso em: mar. 2015.

[7] J. T. Santomé. Globalização e interdisciplinaridade. Porto Alegre: Artmed, 1998.

[8] V. C. O. Aureliano \& P. C. A. R. Tedesco. Avaliando o uso do Scratch como abordagem Alternativa para o processo de ensino-aprendizagem de programação. In: Anais do XX Workshop sobre Educação em Computação, Curitiba/Paraná, 2012.

[9] M. Resnick et al. Scratch: programming for all. Communications of the ACM, vol. 52, no. 11, 2009, pp. 60-67.

[10] A. M. Pazinato \& A. C. Teixeira. O Uso do Software SCRATCH no Desenvolvimento da Aprendizagem e na Interação Construtivista dos Alunos. In: Anais do XI Congresso Nacional de Educação - EDUCERE, Curitiba/Paraná, 2013. 
[11] A. Wilson \& D. C. Moffat. Evaluating Scratch to introduce younger schoolchildren to programming. In: Anais do Workshop of Psychology of Programming Interest Group, Madrid/Espanha, 2010.

[12] A. S. Pinto. Scratch na aprendizagem da Matemática no $1^{\circ}$ Ciclo do Ensino Básico: estudo de caso na resolução de problemas. 2010. Dissertação de Mestrado em Estudos da Criança. Universidade do Minho, Portugal, 2010.

[13] M. Andrade et al. Desenvolvendo games e aprendendo matemática utilizando o Scratch. In: Anais do SBGames, São Paulo/SP, 2013.

[14] ScratchED - Relato de Karen Randall. Embedding Scratch in US History/Geography. Disponível em $<$ http://scratched.gse.harvard.edu/resources/embe dding-scratch-us-historygeography>. Acesso mar. 2015.

[15] R. M. Branch. Instructional Design: The ADDIE Approach. Springer, 2009.

[16] R. K. Yin. Case Study Research: Design and Methods SAGE Publications (5. ed.). 2013.

[17] C. Wohlin et al. Experimentation in Software Engineering. Springer, 2012.

[18] V. R. Basili, G. Caldeira \& H. D. Rombach. Goal Question Metric Paradigm. Encyclopedia of Software Engineering, John Wiley \& Sons, 1994.

[19] PCN, Parâmetros Curriculares Nacionais, Terceiro e Quarto ciclos do Ensino Fundamental, História. MEC. Disponível em: $<$ http://portal.mec.gov.br/seb/arquivos/pdf/pen_5 a8 historia.pdf $>$. Acesso em: mar. 2016.

[20] PROINFODATA. Disponível em: $<$ http://proinfodata.c3sl.ufpr.br/>. Acesso em: mar. 2016.

[21] J. Moreno-León \& G. Robles. Dr. Scratch: a Web Tool to Automatically Evaluate Scratch Projects. In: Proceedings of Workshop in Primary and Secondary Computing Education. London, UK, 2015.

[22] Iniciativa Computação na Escola. Disponível em: $<$ http://www.computacaonaescola.ufsc.br/>. Acesso em: mar. 2016.
[23] J. C. Herz. Joystick Nation. How videogames ate our quarters, won our hearts, and rewired our minds. Princeton, NJ: Little Brown \& Company 1997.

[24] L. O. Millavil. O ensino de história na sociedade do conhecimento: novas relações entre currículo e historiografia. In: Carretero, M. et al. (orgs.). Ensino de história e memória coletiva. Porto Alegre: Artmed, 2007.

[25] Y. Jimenez \& C. Gardner-McCune. Using App inventor $\&$ history as a gateway to engage African American students in computer science. In: Proceedings of Research in Equity and Sustained Participation in Engineering, Computing, and Technology (RESPECT). Charlotte/NC, EUA. 2015. p. 1-2.

[26] R. Marcelino; I. M. Amérco; J. Oliveira; S. Santana. Utilização de mundos virtuais $3 \mathrm{D}$ para a educação básica. In: Proceedings of International Conference on Interactive Computer aided Blended Learning. Florianópolis/SC, 2013. p.159-166.

[27] W. R. Watson; C. J. Mong; C. A. Harris. A case study of the in-class use of a video game for teaching high school history. Computers \& Education, vol. 56, no. 2, 2011.

[28] D. F. P. Conrad; G. Aldana; S. Hough. Animal tlatoque, Attracting middle school students to computing through culturally-relevant themes. In: Proceedings of the 42nd ACM Technical Symposium on Computer Science Education - SIGCSE '11. Dallas/TX, EUA. 2011. p. 453-458.

[29] S. M. Brookhart. How to Create and Use Rubrics for Formative Assessment and Grading. Association for Supervision \& Curriculum Development, 2013. 